http://jmscr.igmpublication.org/home/

ISSN (e)-2347-176x ISSN (p) 2455-0450

crossref DOI: https://dx.doi.org/10.18535/jmscr/v7i10.158

Journal Of Medical Science And Clinical Research

\title{
Anatomical Precontoured Locking Plate versus Reconstruction Plate in Unstable Clavicular Fractures
}

\author{
Authors \\ Prof. Dr R. Neelakrishnan ${ }^{1}$, Dr D.Ganesh ${ }^{2}$, Dr V.Barathiselvan ${ }^{3}$, \\ Dr P.S.Balamurugavel ${ }^{4}$, Dr K.Parasuraman ${ }^{5}$, Dr R.Ravikrishna ${ }^{6}$ \\ ${ }^{1}$ Professor and Head, Department of Orthopaedics, Rajah Muthiah Medical College \& Hospital, \\ Annamalai University \\ ${ }^{2}$ Post Graduate in Orthopaedics, Rajah Muthiah Medical College \& Hospital, Annamalai University \\ ${ }^{3,4,5,6}$ Assistant Professor of Orthopaedics, Rajah Muthiah Medical College \& Hospital, \\ Annamalai University
}

\begin{abstract}
Introduction: For the fixation of unstable clavicular fractures, unique plates are available with merits and demerits. Reconstruction plates are reasonably-priced but their strength and rigitidy had been doubtful. The anatomical pre contoured locking plates offer better stability in comparison with the reconstruction plate.
\end{abstract}

Materials and Methods: We have analyzed prospectively 40 unstable clavicular fractures treated surgically with pre contoured anatomical locking plate (20cases) or reconstruction plate (20 cases) for patients admitted in our institute between June 2018 and Oct 2019. The clinical and radiological results among the reconstruction plate and pre contoured anatomical locking plate have been compared by Quick Disability of the Arm, Shoulder and Hand (DASH) score and plain radiographs, respectively.

Results: The mean time of union was16.3 weeks with the reconstruction plate as compared with 13.4 weeks with the pre contoured locking plate. The Quick DASH score was 32.65 in the reconstruction plate patients and 25.44 in the pre contoured locking plate group. Screw cut out and plate failures were found within the reconstruction plate group which needed removal of implant. The mean follow-up month was 16.44 months (14-31 months). Implant removal was carried out in three patients in the reconstruction group and one patient in pre contoured plate group. 3 nonunion occurred with recon plate and one with pre contoured plate.

Conclusion: Surgical management of unstable clavicle fractures with anatomical pre contoured locking plate results instable fixation, early union, and better results in comparison with the reconstruction plating.

Keywords: anatomical pre contoured plate fixation, quick DASH score, reconstruction plate fixation.

\section{Introduction}

Comminuted displaced midshaft Fractures of clavicle are common injuries across the shoulder girdle. Fractures of the clavicle account for about $2.6 \%$ of all fractures Historically, the clavicle fractures had been managed conservatively ${ }^{1,14}$. The middle-third fractures are common and account for approximately $85 \%$ of all clavicular fractures $^{8}$. The narrow segment of the bone in the middle of shaft combined with usual muscle 
forces acting over it predispose to fracture the bone on this locality. Most clavicle fractures generally unite with any approach of immobilization. ${ }^{1}$ Hence, non-operative treatment initially was the accepted modality of those fractures. But research have shown a high rate of non union ${ }^{7,9,10}$ and symptomatic malunion ${ }^{13}$ and shortening $^{15}$ when the displaced fractures are treated conservatively. ${ }^{2}$ Other shortcomings of non-operative treatment had been functional impairment of the shoulder and a non-cosmetic bump at the bottom of the neck possibly due to shortening and displacement of the clavicle and exuberant callus formation. Functional results of unstable clavicle fractures isn't simply related to its union, but additionally to its length. To maintain the length plate is the ideal implant than a nail ${ }^{4}$. Clavicle acts as a "strut" that keeps the upper limb away from the torso for efficient shoulder and upper limb function, while also transmitting forces from limb to the trunk. Thus, displaced or comminuted fractures carry a chance of symptomatic malunionand poor functional outcome with cosmetic deformity. Plate fixation provides immediate rigid stabilization and pain relief and facilitates early mobilization. ${ }^{3}$ Regarding plate osteosynthesis the implant used mainly are reconstruction plate and pre contoured locking plates. Restoration of length and alignment achieved only by way of surgical strategies $^{12}$ which are not achieved by conservative treatment. Good outcome with high union rates and minimal complications has been mentioned with surgical fixation of the unstable clavicle fractures with anatomical locking plate compared to reconstruction plate. ${ }^{4}$ However, operative management got its disadvantages like infection at surgical site, hypertrophic scar, hardware prominence and another surgical treatment for implant removal. Hence, in this study we compare the outcome of unstable clavicle fractures fixed with reconstruction plate and anatomical locking plate., ${ }^{5,6}$ The implant used in all our patients was a pre-contoured $3.5 \mathrm{~mm}$ superior clavicle anatomical locking compression plate and $3.5 \mathrm{~mm}$ reconstruction plate. Another set of $2.7 \mathrm{~mm}$ lag screws was always kept ready, in order to lag any unstable butterfly fragment(s), if the need arose.

\section{Materials and Techniques}

Our study from June 2018 to Oct 2019 prospectively analysed 40 cases of unstable clavicle fractures treated with anatomical locking plate 20 patients and reconstruction plate 20 cases. Inclusion criteria were age among 20 to 50, closed displacement $>2 \mathrm{~cm}$ unstable clavicle fracture with shortening $>2 \mathrm{~cm}$ with or without comminution falling under Robinson category as kind 2B1 and 2B2, Segmental fractures, Open fracture, Impending compound fracture with soft tissue compromise, bilateral clavicular fractures

\section{Operative technique}

The surgery was performed under regional block or general anaesthesia when needed. The patient was positioned supine, with the head and neck tilted away from the surgical site with a bump placed behind the scapula to aid in reduction. The arm was prepared in the field to allow for traction and manipulation to assist in the reduction. Preoperative intra-venous antibiotic (Cefotaxime 1 gram) was given to the patient, at least 30 minutes before making the skin incision. The skin inferior to the fracture site was incised after pulling it up to the fracture site. As the skin was released, it fell 1 to $2 \mathrm{~cm}$ below the clavicle and prevented the wound from being in contact with the plate on the clavicle. The subcutaneous tissue and platysma muscle were kept together as one layer and extensively mobilized, especially proximally and distally. Sharp dissection was taken down to the bone, with care to identify, and if possible, preserve the cutaneous supraclavicular nerves. When deemed necessary, they were sacrificed. The myofascial layer over the clavicle was incised and elevated in one continuous layer comminuted fragments, especially the often seen anterosuperior fragment was teased back into position, as much as possible, maintaining its soft tissue attachments. The fractured bone was reduced and 
the reduction held with the aid of reduction clamps. The reconstruction plate was contoured to the shape of clavicle. The pre-contoured plate matching the clavicle was placed on superior position. Biomechanical studies have shown this position toprovide best stability. The clavicle was drilled cautiously keeping in mind the relation of the subclavian vessels to the inferior surface to clavicle. Ideally 3 (atleast2) bicortical screws on either side of the fracture were needed; lag screws were used wherever needed to reduce the communited fragments. Once plating was completed, the fascia was repaired over the plate. Skin incision was closed. Antiseptic dressing was applied, and the arm was rested in an arm sling postoperative the patient was kept in the postoperative recovery ward, under observation. Vitals were monitored.

\section{Assessment of Treatment Results}

The patients followed at 6 weeks and at 3, 6, 12 months. At each visit, and for any complications, anteroposterior radiographs were taken. Radiographic union was defined as cortical bridging throughout the fracture so that fracture line is not visible. Functional evaluation done using the DASH score. Statistical evaluation was done. $\mathrm{p}<0.05$ was considered significant.

\section{Results and Observation}

It has been noted that fractures were found in the working age-group mostly with male predominance and dominant side. Road traffic accidents contributed to most of the injuries. The patients age, gender, cause of injury, and fracture pattern were not statistically significant between the two groups $(\mathrm{p}>0.05)$. The mean operative time was $85.1 \mathrm{~min}$ (SD $19.4 \mathrm{~min}$ ) within the reconstruction group, and $59.3 \mathrm{~min}$ (SD $12.6 \mathrm{~min}$ ) in the anatomical locking plate patients revealing intergroup differences. The need for lag screw is more for reconstruction plate than anatomical plate. The shorter time is particularly due to no need for plate contouring as compared with the reconstruction plate group in which maximum of the time spent in contouring the plate to the bone curvature. Bony union occurred at 16.3 weeks (range: 8-31 weeks) and 13.2 weeks (variety: 818 weeks) in the reconstruction and anatomical locking plate, respectively, indicating intergroup difference $(p<0.05)$. In the clinical assessment, the reconstruction group and anatomical locking group showed a mean Quick DASH score of 32.65 (SD 1/4 9.4 points) and 25.44 points (SD 1/4 12.7 points), respectively ( $\mathrm{p}>0.05$ ). Postoperative complications were noted in both the groups. In the reconstruction group, there was hypertrophic scarring without pain in 3 cases, shoulder movement restriction in 2 cases, painful shoulder in a single case, screw pull out in 2 cases, and plate failure in one case. In the anatomical locking plate group one screw pull out was there and Infection and non union in 1 person due to diabetes.

Table-1: Demographic profile

\begin{tabular}{|l|c|c|c|}
\hline & $\begin{array}{c}\text { Reconstruction } \\
\text { group }\end{array}$ & $\begin{array}{c}\text { Pre contoured } \\
\text { plate group }\end{array}$ & p value \\
\hline Age & 29.5 & 27.5 & $>0.05$ \\
\hline Sex & $12: 8$ & $13: 7$ & $>0.05$ \\
\hline Dominant side & $84 \%$ & $92 \%$ & $>0.05$ \\
\hline RTA & 14 & 15 & \\
Fall & 6 & 4 & $>0.05$ \\
Sports injuries & 0 & 1 & \\
\hline Type of fractures & 7 & 5 & $>0.05$ \\
Type b1 & 13 & 15 & \\
Type b2 & & & \\
\hline
\end{tabular}


Table-2: Outcome Analysis

\begin{tabular}{|l|c|c|c|}
\hline & Reconstruction plate & Anatomical plate & P value \\
\hline Operative time (min) & 85.1 & 59.3 & $<0.5$ \\
\hline Bone union period (weeks) & 16.3 & 13.2 & $<0.5$ \\
\hline Quick DASH score & 32.65 & 25.44 & $>0.5$ \\
\hline Plate prominence & 3 & 1 & \\
\hline Hypertrophicscar & 2 & - & \\
\hline Implant removal & 2 & 1 & \\
\hline Non union & 2 & 1 & \\
\hline Screw pull out & 3 & 1 & \\
\hline
\end{tabular}

Fig-1: Case Illustration
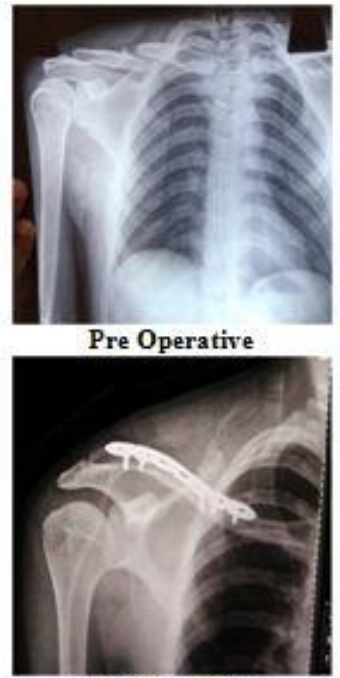

Post Operative

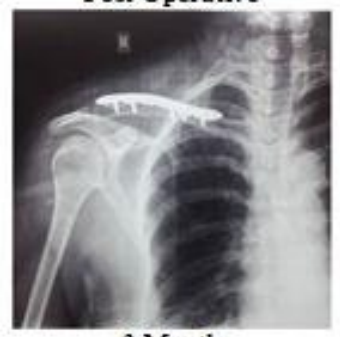

3 Month

\section{Discussion}

Clavicle fractures are normally treated conservatively. In a study conducted to analyze the results of conservative treatment of displaced midshaft fractures of clavicle by Michael et al they detected residual deficits in shoulder strength, especially endurance strength, in this patient population. ${ }^{7,8}$ They also found clavicular shortening was associated with a decreased abduction strength $^{11}$, and shortening of $>2 \mathrm{~cm}$ was associated with a patient dissatisfaction. A.H Qvist et al compared plate fixation with non operative treatment of displaced midshaft clavicular fractures and concluded pre contoured and locking plates results in faster functional
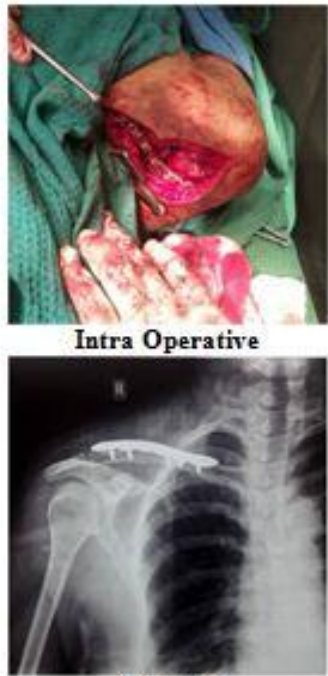

1 Month

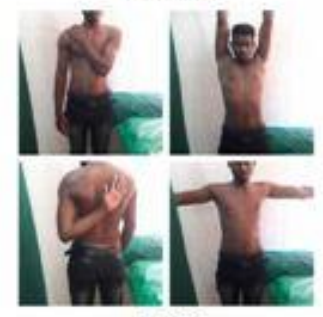

ROM

recovery and a higher rate of union when compared with non operative management.

Fig-2: 3D Reconstruction of plate

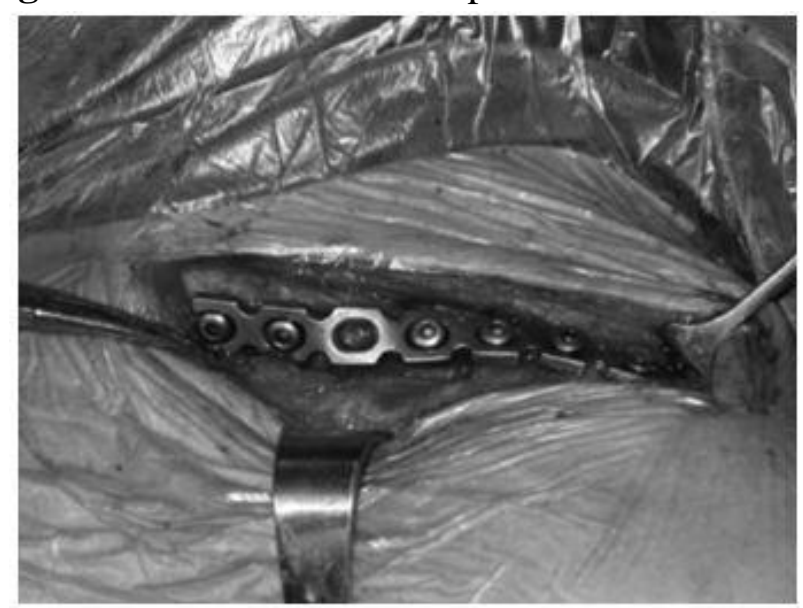


Reconstruction plates have fallen into disfavor, since they are susceptible to deformation at the fracture site, leading to malunion. In study by J-W Shen and others concluded a three dimensional reconstruction plate is better than $2 \mathrm{D}$ plate which is placed superiorily. To overcome this Site specific pre contoured locking plates ${ }^{16,17}$ are now available. Hardware prominence was less when pre contoured plate was used. Tania Reisch et al in their research in 100 patients found the new pre contoured locking plate fit to the anatomical shape of the clavicle. The implant seems to be reliable regarding handling and complications. ${ }^{9,10}$ Hardware removal rates are comparable to other studies with a pre-contoured plate and lower compared to non pre-contoured. In a study by Alexander et al they found the pre contoured plates significantly diminish hard ware prominence. Corine van beck et al compared superior plating of non contoured and pre contoured plating and found superior pre contoured plates have low incidence of plate prominence and hardware removal. McKee (2010) reported that primary plating of displaced middle third clavicle fractures has better outcome, quick functional recovery, and decreased rate of non union and symptomatic malunion when compared to non operative treatment. Two of the most commonly used techniques for operative treatment are open reduction and internal fixation with plate and intramedullary nail fixation. ${ }^{11-14}$ Nidhinarsaria in his study found elastic intramedullary nailing is a safe, minimally invasive technique with a lower complication rate but Arno frigg and others studied about the complications like nail breakage, medial migration, hardware irritation. The sigmoid shape of the clavicle poses specific problem in the design and insertion of intramedullary devices and static locking is not possible with the implants currently available. There is biomechanical evidence to suggest that plate fixation provides a stronger construct than intramedullary fixation. Functional results of unstable clavicle fractures isn't simply related to its union, but additionally to its length. To maintain the length plate is the ideal implant than a nail. Clavicle acts as a "strut" that keeps the upper limb away from the torso for efficient shoulder and upper limb function, while also transmitting forces from limb to the trunk. Thus, displaced or comminuted fractures carry a chance of symptomatic malunion and poor functional outcome with cosmetic deformity. Plate fixation provides immediate rigid stabilization and pain relief and facilitates early mobilization. ${ }^{15-17}$ Most commonly the plate is implanted on the superior aspect of clavicle. Currently the implants most commonly used are locking plates.

Reconstruction plates have fallen into disfavor, since they are susceptible to deformation at the fracture site, leading to malunion. In study by J-W Shen and others concluded a three dimensional reconstruction plate is better than $2 \mathrm{D}$ plate which is placed superiorily. To overcome this Site specific pre contoured locking plates are now available. Hardware prominence was less when pre contoured plate was used. Tania Reisch et al in their research in 100 patients found the new pre contoured locking plate fit to the anatomical shape of the clavicle. The implant seems to be reliable regarding handling and complications. Hardware removal rates are comparable to other studies with a pre-contoured plate and lower compared to non pre-contoured. In a study by Alexander et al they found the pre contoured plates significantly diminish hard ware prominence. So in this study we compared reconstruction plate with anatomical locking plate for unstable clavicle fractures. Corine van beck et al compared superior plating of non contoured and pre contoured plating and found superior pre contoured plates have low incidence of plate prominence and hardware removal. Inclusion criteria were age among 20 to 50 , closed displacement $>2 \mathrm{~cm}$ unstable clavicle fracture with shortening $>2 \mathrm{~cm}$ with or without comminution falling under Robinson category as kind $2 \mathrm{~B} 1$ and 2B2, Segmental fractures, Open fracture, Impending compound fracture with soft tissue compromise, bilateral clavicular fractures. In our study the time taken for union is 
significantly lower for anatomical locking plate than reconstruction plate. Patients return early to routine works in anatomical plate group when compared to reconstruction plate group.

\section{Conclusion}

So we conclude from our study anatomical locking plate used for fixing unstable clavicle fractures results in early and good fracture union and early return to routine activities when compared to reconstruction plate.

\section{References}

1. Paffen PJ and Jansen EW. Surgical treatment of clavicular fractures with Kirschner wires: a comparative study. Arch Chir Neerl 1978; 30(1): 43-53.

2. Muller ME, Allgower M, Schneider R, et al. Manual of internal fixation: Techniques recommended by the AO-ASIF group. 2nd ed. New York: Heidelberg, 1979, p. 166.

3. Lee CJ, Cho WH, Chang HG, et al. Operative treatment of the diaphyseal fracture of clavicle (fresh fracture and symptomatic delayed union or non-union). J Korean Orthop Assoc 1990; 25(1): 117-122.

4. Chu CM, Wang SJ, and Lin LC. Fixation of mid-third clavi- cular fractures with Knowles pins: 78 patients followed for 2-7 years. Acta Orthop Scand 2002; 73(2): 134-139.

5. Hill JM, McGuire MH, and Crosby LA. Closed treatment of displaced middle third fractures of the clavicle gives poor results. J Bone Joint Surg Br 1997; 79(4): 537-539.

6. Zlowodzki M, Zelle BA, Cole PA, et al. Treatment of acute midshaft clavicle fractures: systematic review of 2144 fractures: on behalf of the Evidence-Based Orthopae- dic Trauma working group. J Orthop Trauma 2005; 19(7): 504-507.

7. Neer CS 2nd. Nonunion of the clavicle. J Am Med Assoc 1960; 172(10): 1006-1011.
8. Rowe CR. An atlas of anatomy and treatment of midcla- vicular fractures. Clin Orthop Relat Res 1968; (58): 29-42.

9. Robinson CM, Court-Brown CM, McQueen $\mathrm{MM}$, et al. Esti- mating the risk of nonunion following nonoperative treat- ment of a clavicular fracture. J Bone Joint Surg Am 2004; 86(7): 1359-1365.

10. Neer CS2nd. Fractures of the distal third of the clavicle. Clin Orthop Relat Res 1968; 58: 43-50.

11. Howard FM and Shafer SJ. Injuries to the clavicle with neu- rovascular complications: a study of fourteen cases. J Bone Joint Surg Am 1965; 47(7): 1335-1346.

12. Ring D, Perey BH, and Jupiter JB. The functional outcome of operative treatment of ununited fractures of the humeral dia- physis in older patients. J Bone Joint Surg Am 1999; 81(2):177-190.

13. Kim D, Lee D, Jang Y, et al. Effects of short malunion of clavicle on in vivo scapular kinematics. J Shoulder Elbow Surg 2017; 26: e286-e292.

14. Postacchini R, Gumina S, Farsetti P, et al. Long-term results of conservative management of midshaft clavicle fracture. Int Orthop 2010; 34: 731-736.

15. Goudie EB, Clement ND, Murray IR, et al. The influence of shortening on clinical outcome in healed displaced midshaft clavicular fractures after nonoperative management. J Bone Joint Surg [Am] 2017; 99: 1166-1172.

16. Perren SM. Evolution and rationale of locked internal fixator technology: introductory remarks. Injury 2001; 32(Suppl 2): B3-B9.

17. Van Beek C, Boselli KJ, Cadet ER, et al. Precontoured plating of clavicle fractures decreased hardware-related complica- tions? Clin Orthop Relat Res 2011; 469: 3337-3343. 